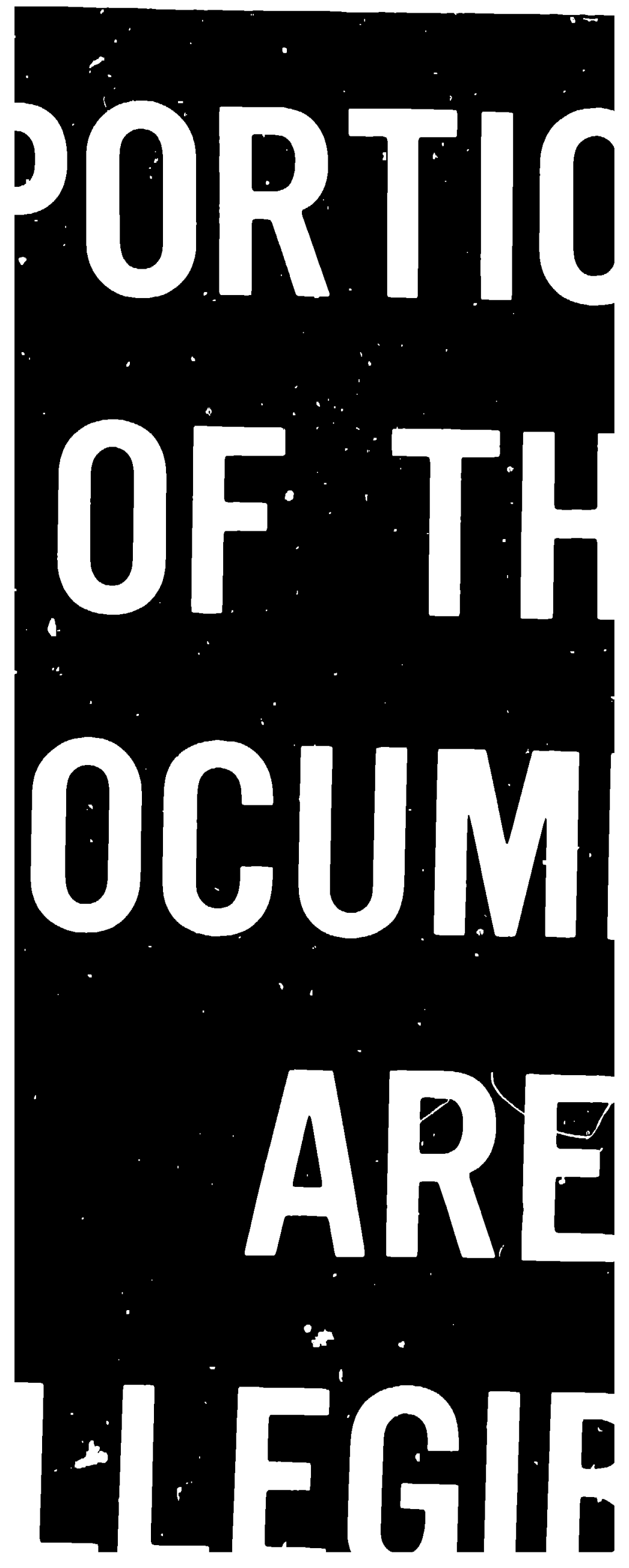


TITLE: HIGII-CURRIN'T DINSITY (OTL.S FOR HIGII-RADIATTON IENVRTONMFN'S

AUTHOR(S): Aluxinder llarvey

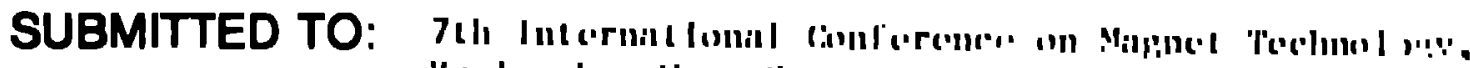

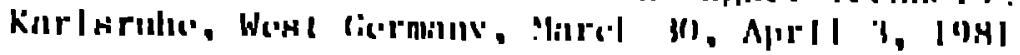
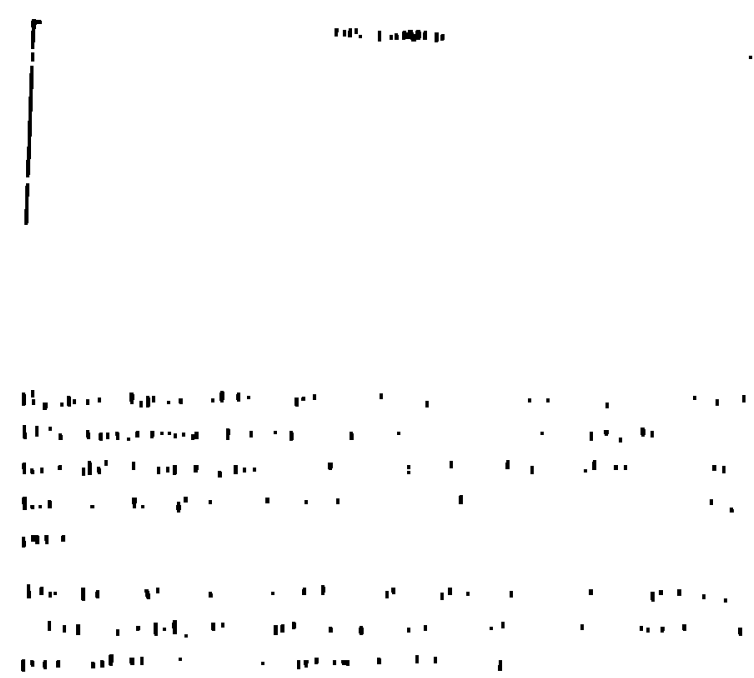
SuMPinity

This paper concentrates on the protletrs of providing normal (that is, milleuderennduc tiric; magrie: coils for vresent and stort-term-fulure requirements where significant riaiation doses are irivolven. Pri-

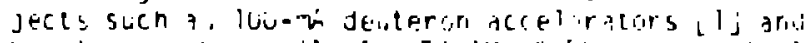

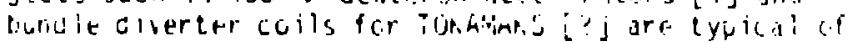

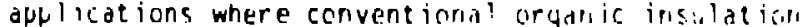

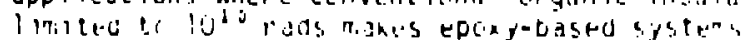
dilciceptable. Moreover, tevere in present-day acce :erater radiation leve is can be high revidall ti :

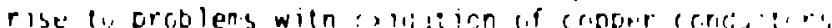

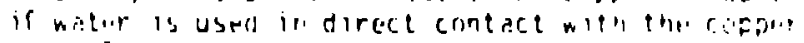

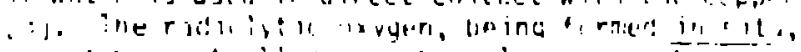

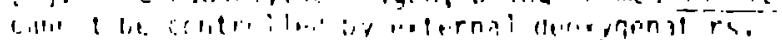

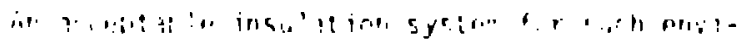

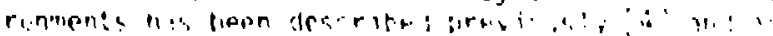

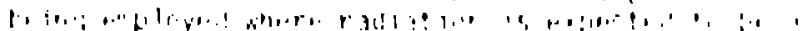

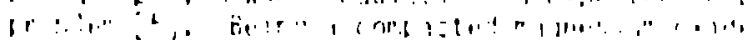

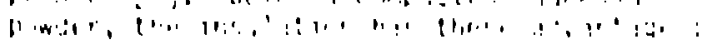

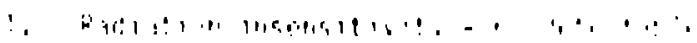

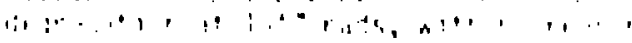
$\because \ldots, 1, \ldots, \ldots, \ldots$ i. i.

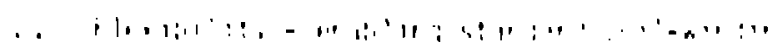

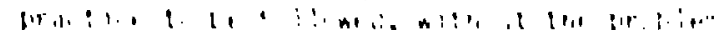
i $1, \ldots+\ldots, 1, \cdots$

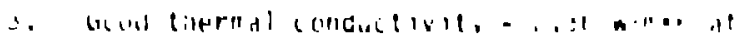

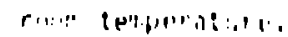

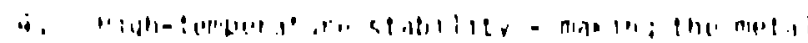

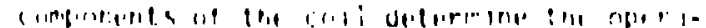

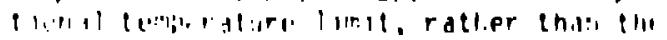

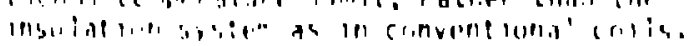

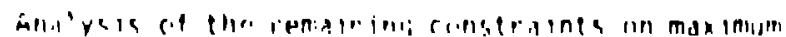

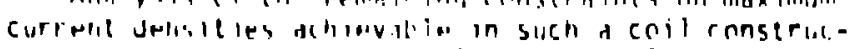
licie, using compuere cospa, leade to coil configura-

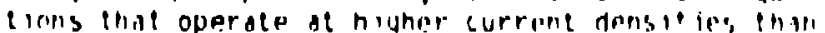
are usually teume in direcily conled coils. It also becomes clear that the cable can be designat. not neressarily to maximize the "back ing fartor" by decreasing irsulation ard sheath thictness, bui to cotimige the thermal conetitions within the coil pach. age. The operuling leniperifure limit is determinerl by the accedable oxidation rate of the surface. exsused metal on the coll.

\footnotetext{
Manucitot rece'ved March $31,|y k|$ The author is wilh the Accelerstor lechnoloyy Uivision at the Los Alamos Nalienil Laboratory, 1. O. Bur 166J, Los Alamos. NM 8734b

"Work performad unuer the auspices of the US Unpartinent of Inergy.
}

An cyampie of the therrial arazyeis of une cri: configliration is given. The jopreach taken at L.

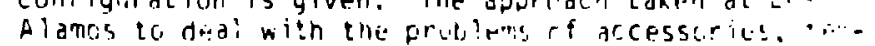
peracure sensors for pxumple, mrich are of terl t: intractable. as the coil itself, is cutlinece.

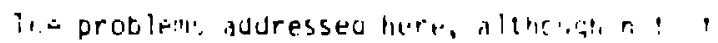

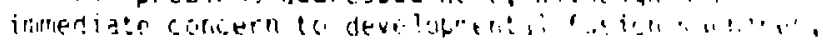

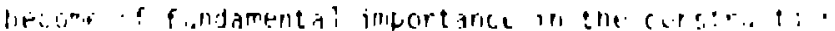

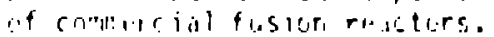

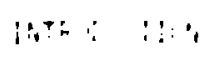

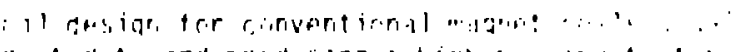

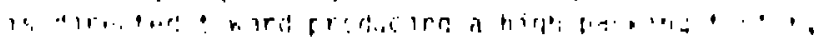

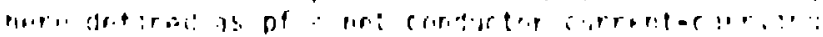

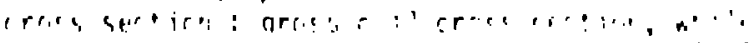

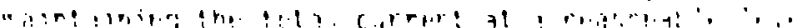

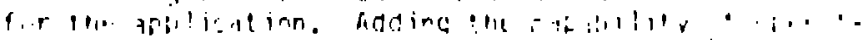

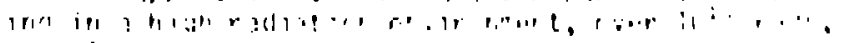

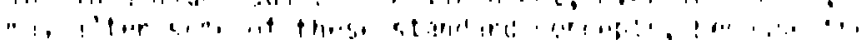

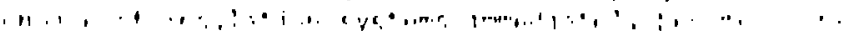

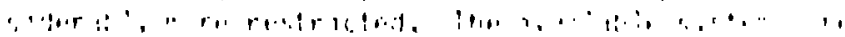

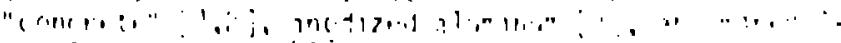

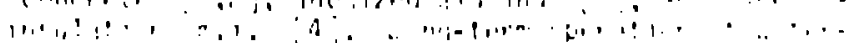

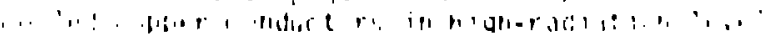

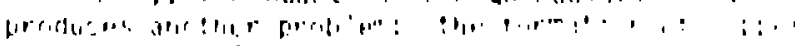

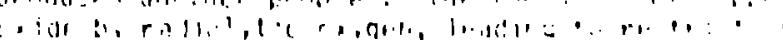

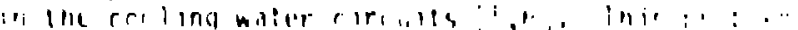

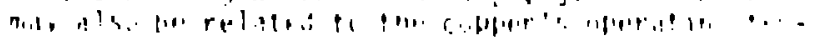

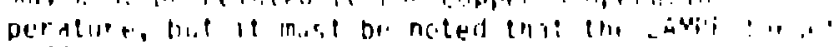

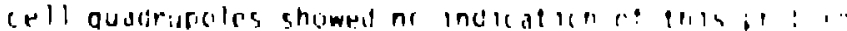

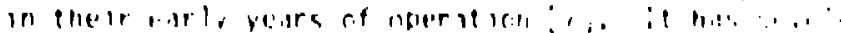

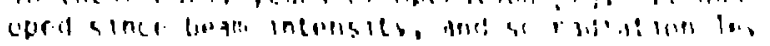
havi: rican lo: theier presignt : avils.

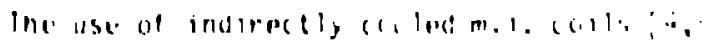

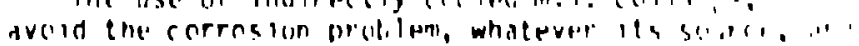

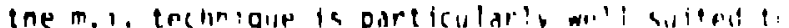

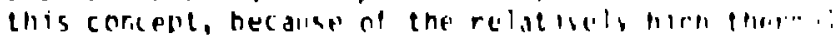

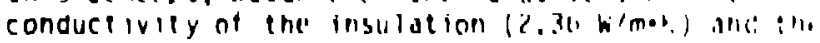
copper-jak keted concetruction that prisilles a met; $\cdots$ hedi path to the cocling sink. Inis pafer dreserill. the destan notimisation at such a rili. The ind advantages of : he mplnod may be worth ment imilna:

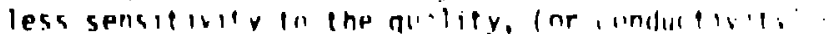

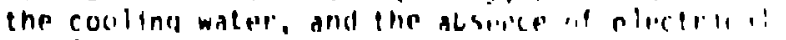
insulatnre in the cooling water system.

\section{COII. OLSIGN}

All applicat inr requir ing radiat fin-harcfeiling: I the maqnet coll is the bean transport line foll the Fusion Matorials Irradiation Test (FMIT) [Y acceleratur-target, where the final quadrubnlus "ar" exposed to not only the estimaled 3-wA/m deuterin spill, but also to back-strmaning neutroms frum the tarqet $[10]$. 
The magnet cross section chosen is shown in Fig. 1. It provides a compact structure, easily fabricated for 4-fold symetry, yet can be split readily on the horizontal centerline for remote access to the vacuum system. The coil has two layers of 13.5-mm square solid m.i. cable wound on top of a layer of cooling tubing, which therefore cocls the tron parts of tne magnet, removing the radiation-deposited heat.

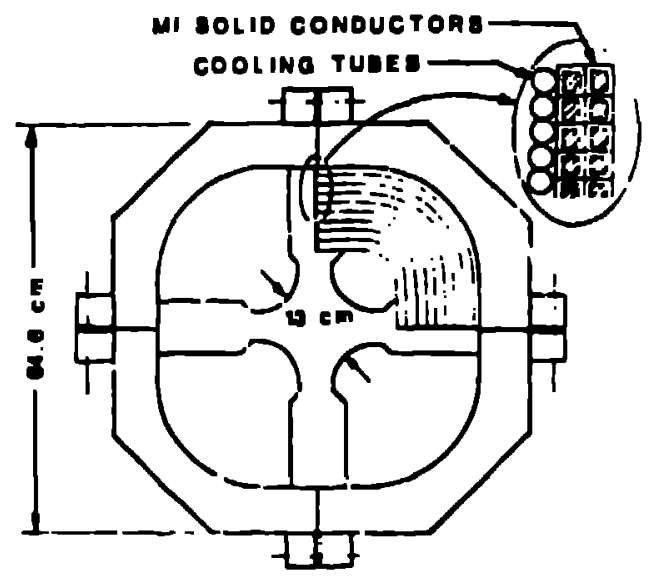

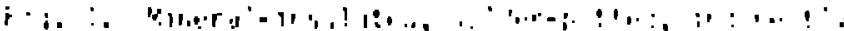

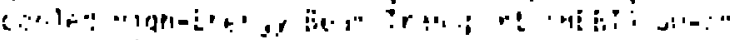
i. id is.

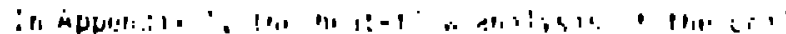

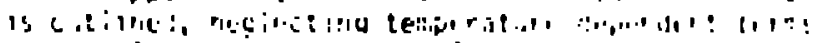

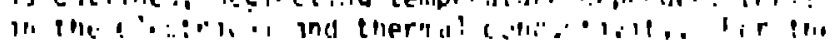

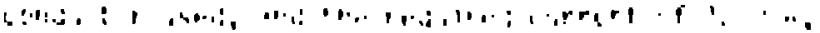

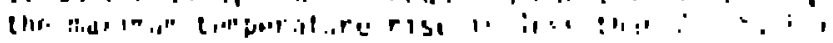

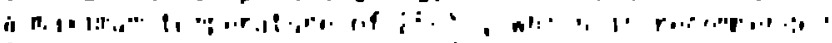

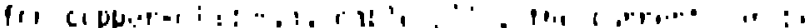

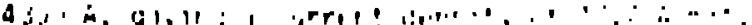

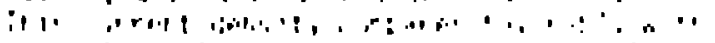

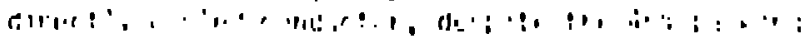

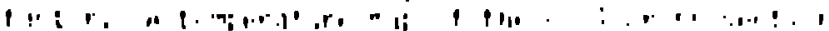
14.

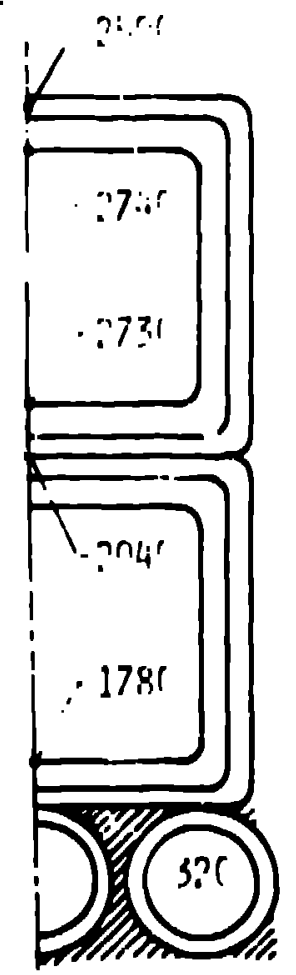

f lu. I. Ipmperatura mali.

\section{FUTURE DEVELOPMENT}

The fuston program leads to requirements for coils of much $n$ igher current ratings than that described above [12]. Meet ing these requirements calls for some changes in m.:. cable technology. Existing cables are made by minor changes in the manufacturing process for conventional m. 1 . cables; cables for $h i g h$ power coils will require careful optimization if the cable parameters. Examination of $(A-1)$ in the Appendix shows the following features.

1. The caule should be rectangular, becaluse the conductor width, Hc, appears only in the denor inator.

2. There will be an optimum value of sheat' thickness, is, for each co!l.

3. A minimian insulatinn :hickness, $t i$, is

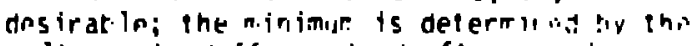
volt age ctandoff requierd after wing i:

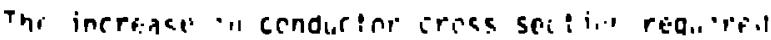

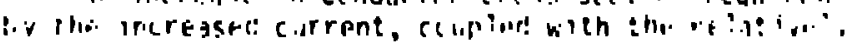

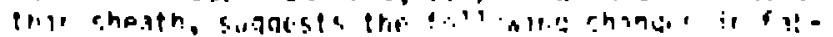

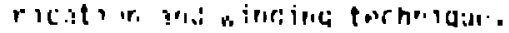

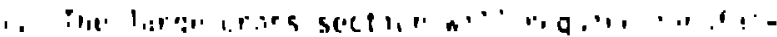

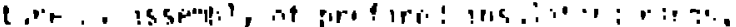

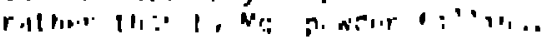

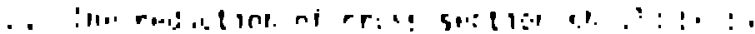

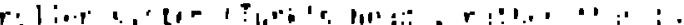

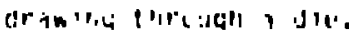

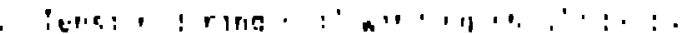

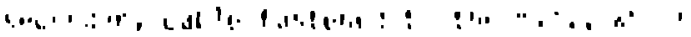

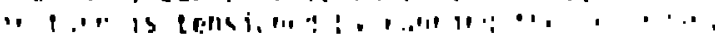

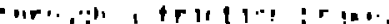

$$
\therefore: \text { : L : : }
$$

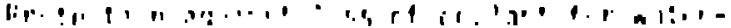

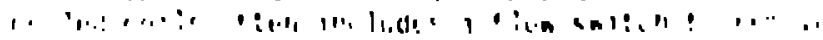

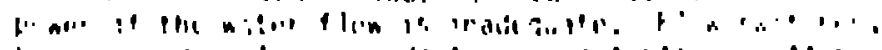

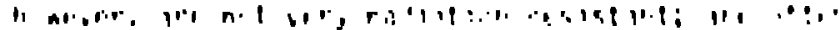

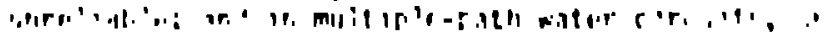

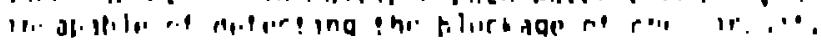

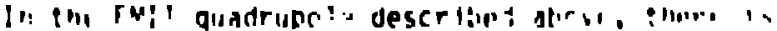

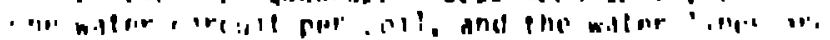

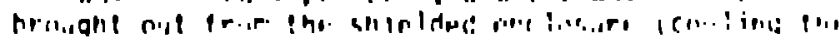

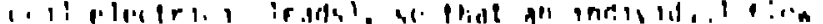

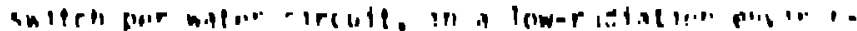

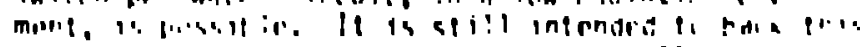

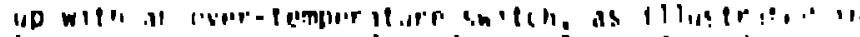

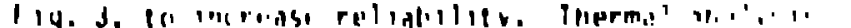

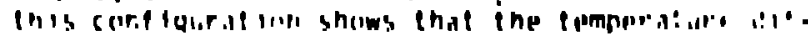

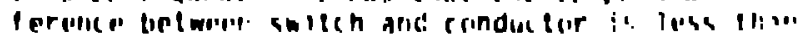

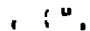

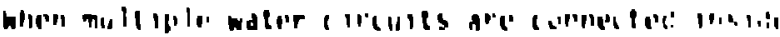
A mighel, the feliendence on temperature shifolles rlsis, hec duse these swilches are the only dewil.. small erough lo install. Thesp can be madp marer effectivi afid reliable hy using severd awitches with an auction-based deciston circult: in Les $\$$ laincs iw cut of three switches determine whether the conliny is ndequote. The thrge switches ore from differeni manufacturers, entirely incraante, to necroso the poss'bllley of a commn tallury mode. 


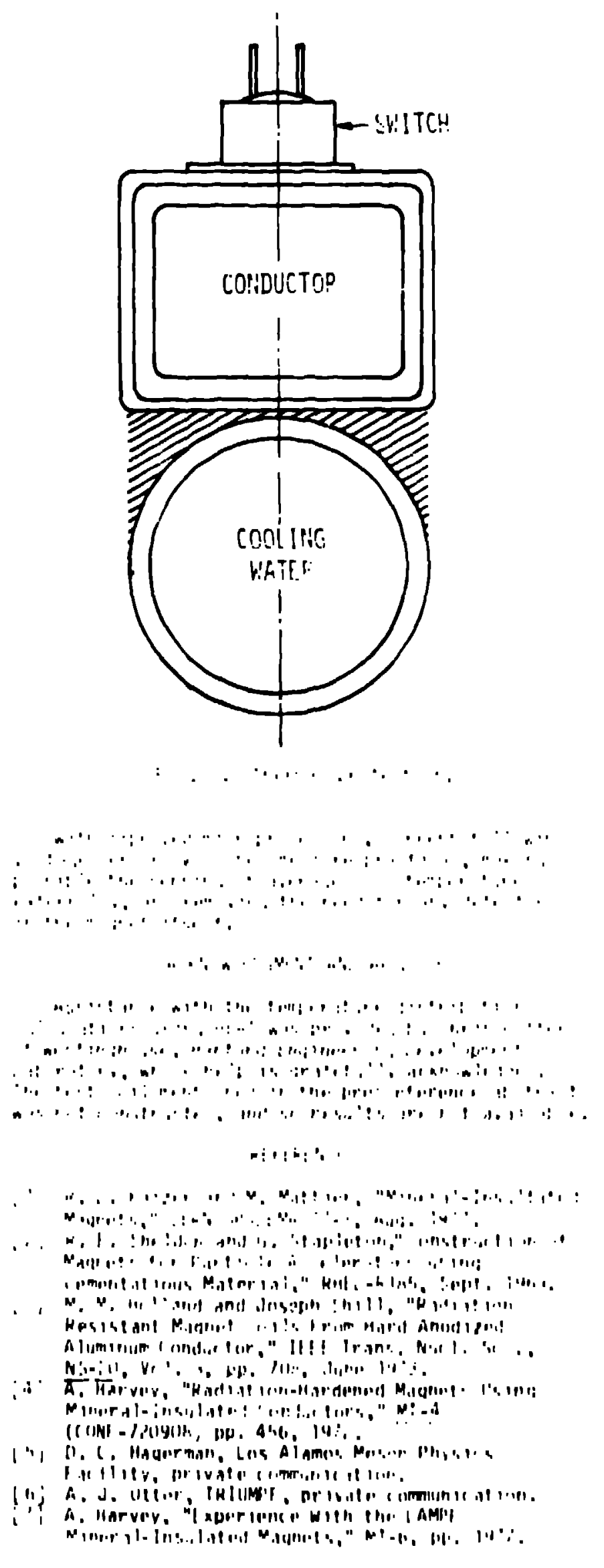

$\because \because$ S. Gerar, "vigrett! nitn viner=i-lns,iate: . at 5...li, Ni-5, fo. iia, 1975 .

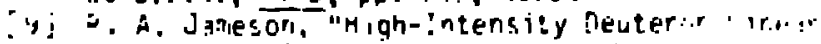

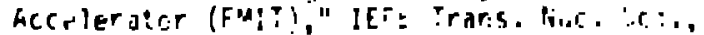
N?-26, Vel. 3, pp. ;ye6, vune 1979 .

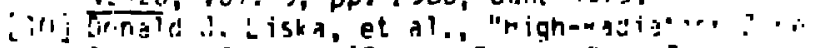

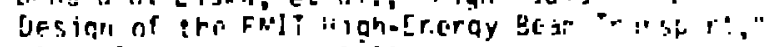
1.:-ith-8!-170. March lykel.

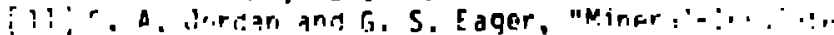

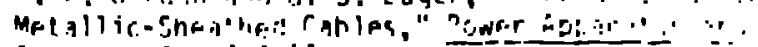

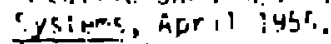

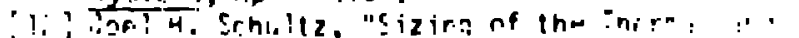

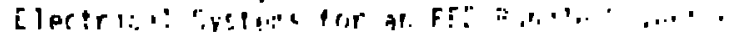

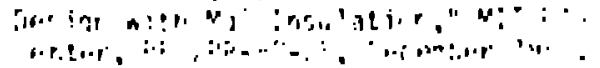

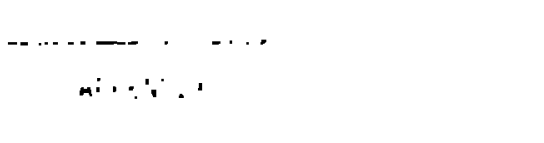

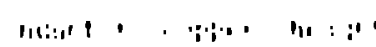

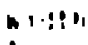

in.

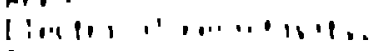

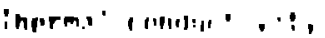

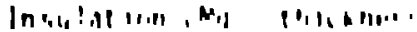

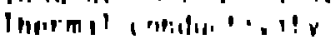

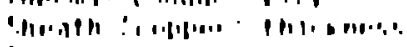

Ihremal a omeded lo lev

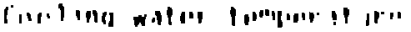

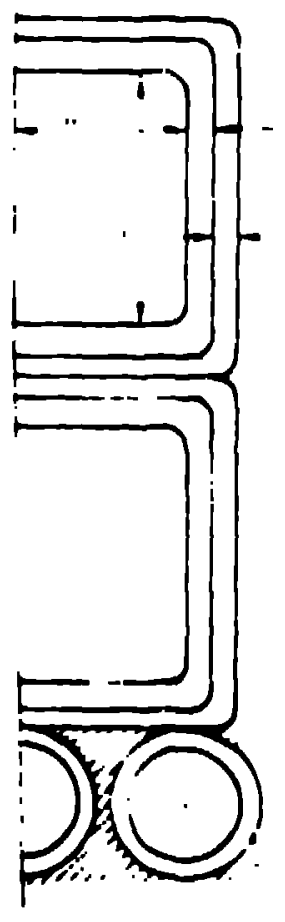

then line une longell.

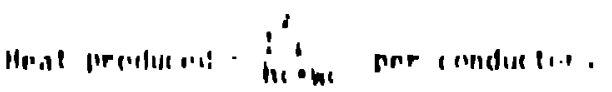

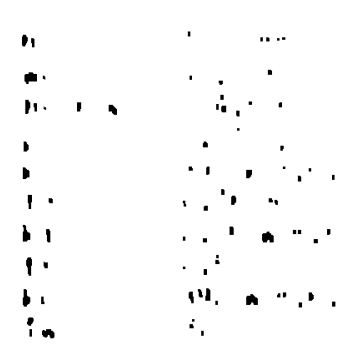


Temperature rise of upper conductor = averaye

temperature of sheath $+r$ ise in insulation

- upper emperature $r$ ise of lower sheath $+1 / 2$ temperature rise in upper sheath + rise in

insulation.

$=\frac{l^{2} p}{h c w c} \frac{1.5}{t s+1, c} \quad n L+i t i+d s$

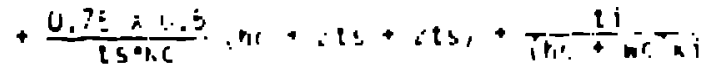

Therefirt, the temperature of the upper cond.deto inhich will rict differ mich fron that at inf tep

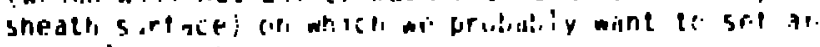
upuet '19.16, Lerr. anifs:

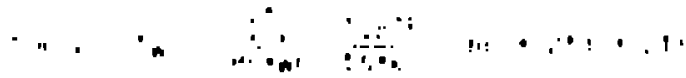

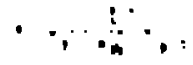

